Anna Katharina Mangold

\title{
Gemeinschaftsrecht und deutsches Recht
}

Die Europäisierung der deutschen Rechtsordnung in historisch-empirischer Sicht

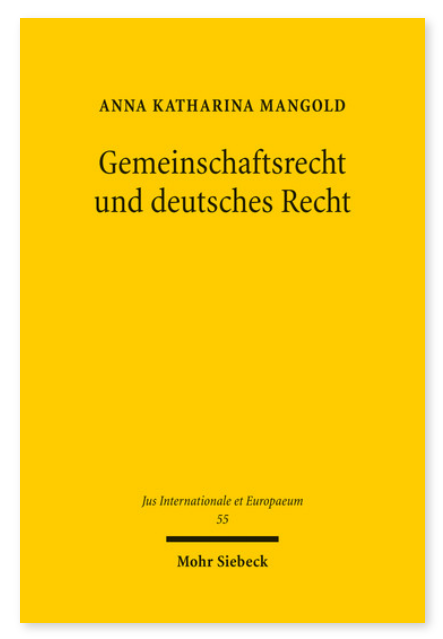

2011. XXII, 586 Seiten. JusIntEu 55

ISBN 978-3-16-151754-9

DOI 10.1628/978-3-16-151754-9

eBook PDF 109,00€

ISBN 978-3-16-150650-5

fadengeheftete Broschur 109,00€
Das europäische Gemeinschaftsrecht hat das bundesrepublikanische Recht von Beginn an maßgeblich mitgeprägt. Die Europäisierung ist neben Konstitutionalisierung und Internationalisierung der dritte zentrale Entwicklungsstrang der deutschen Rechtsentwicklung. Anna Katharina Mangold zeichnet die Entwicklung des Gemeinschaftsrechts und seines Einflusses auf die deutsche Rechtsordnung im historischen Verlauf nach. Die Europäisierung erfasst alle Bereiche der deutsche Rechtsordnung: Rechtswissenschaft, Juristenausbildung, Legislative, Exekutive und Judikative. Mithilfe empirischer Methoden wird die Europäisierung dieser verschiedenen Bereiche objektiv dargestellt.

Die historisch-empirische Sicht auf die Europäisierung erlaubt eine neue Systematisierung der Einwirkungsmechanismen in Umsetzungsrecht, föderales Durchsetzungsrecht und ungesteuerte Anpassungsprozesse. Zugleich zeichnet die Arbeit ein Bild des europäisierten deutschen Rechts.

Anna Katharina Mangold ist Professorin für Europarecht an der Europa-Universität Flensburg.

Jetzt bestellen:

https://mohrsiebeck.com/buch/gemeinschaftsrecht-und-deutsches-recht-9783161517549?no_cache=1 order@mohrsiebeck.com

Telefon: +49 (0)7071-923-17

Telefax: $+49(0) 7071-51104$ 